REVISTA DE DERECHO UNED, NÚM. 11, 2012

\title{
LA HIDALGUÍA DE SOLAR CONOCIDO: NORMAS JURÍDICAS Y DOCTRINA
}

\author{
THE HIDALGUÍA OF SOLAR CONOCIDO. LEGISLATION \\ AND DOCTRINE
}

Julio García-Gabilán SANGIL

Abogado

Resumen: La inclusión de la calificación de «hijodalgo de solar conocido» en los padrones de la moneda forera y del servicio ordinario, no se ajustaba estrictamente al mandato legal que determinaba los términos precisos que debían emplearse en su elaboración.

Además de proclamar un rango jerárquico superior entre los exentos tributarios, el uso de esta calificación en aquellos documentos, parece haber tenido repercusiones favorables en cuanto a la admisión de esta clase de hidalguía como una vía de prueba de la propiedad al margen de los procedimientos establecidos por la pragmática de Córdoba de 30 de mayo de 1492, cuestión sumamente debatida por la doctrina de los siglos XVI y XVII.

Abstract: The inclusion of the qualification of «hijodalgo de solar conocido» in the census of the «moneda forera y servicio ordinario», did not conform exactly to the legal mandate establishing the terms that should be used in its preparation.

In addition to proclaiming a higher hierarchical rank between subjects exempted from taxes, the use of this term in those documents had favourable effects in relation to the admission of this kind of «hidalguía» as a means to prove the propierty, outside the procedures established by the pragmatics of Córdoba on May 30, 1492, question debated by the doctrine of the 16th and 17th centuries. 
Palabras-clave: Solar, hidalguía de solar, propiedad, prueba, calificaciones, padrones.

Keywords: Solar, hidalguía de solar, property, test, tax rolls.

Recepción original: 11/09/2012

Aceptación original: 18/09/2012

\section{LA HIDALGUÍA DE SOLAR. CONCEPTO Y ELEMENTOS DEFINIDORES}

El concepto de hidalguía de solar constituye uno de los piélagos más profundos de la teoría nobiliaria. La necesidad de determinar su concepto se apoya en dos poderosas razones. En primer lugar, las alusiones a la hidalguía solariega son reiteradas en los juicios petitorios. Por otra parte, a pesar de la cláusula de cierre establecida por la pragmática de Córdoba de 1492, que prohibía expresamente la declaración de hidalguía en propiedad o en posesión al margen de lo en ella preceptuado ${ }^{1}$, un sector doctrinal vio en el solar una vía para obtener la declaración de la propiedad sin necesidad de acreditar la concurrencia de la posesión, posibilidad que tenía su principal fundamento en el tenor del proemio de esta pragmática y en la de Enrique III de 14 de abril de 1403, conocida con el nombre de pragmática de Tordesillas².

El primer problema con el que nos encontramos al abordar este tema, radica en la ausencia de una definición jurídica del solar, ausencia que fue denunciada por nuestros tratadistas, tanto en relación con el derecho castellano, como con el derecho común ${ }^{3}$. Lógica consecuencia de esta ausencia, fue la falta de unanimidad en cuanto a lo que debía entenderse por «hijodalgo de solar conocido».

\footnotetext{
${ }^{1}$ Nueva Recopilación, libro II, título XI, ley VIII -D. Fernando e Doña Isabel, en Córdoba, 30 de mayo de 1492-.

2 «...aquellos que fueren notorios hijosdalgo, de solar conocido, o huuieren auido sentencia de cómo son dados por Hijosdalgo, según del tenor de la ley q hizo el Rey don Juan mi señor y padre, y después de la tal sentencia estuuieren y estan en posesión, de la hidalguia, que a estos tales que les sea guardada su franqueza y hidalguia...». Cfr. Nueva Recopilación, libro II, título XI, ley IX -D. Enrique III en Toro, año 1398, y sobrecarta del mismo monarca en Tordesillas el 14 de abril de 1403-.

${ }^{3}$ Vid. García de Saavedra, J.: Tractatus de Hispanorum nobilitate, et exemptione, sive ad pragmaticam Cordubensem, quae est l. 8, título II, libro II Novae Recopilat., Madrid, viuda de Fernando Correa, 1622, glosa XVIII, núm. 1. En cuanto a la falta de definición en el derecho común, Vid. Ibid., núm. 5.
} 
Para precisar el concepto de solar, los autores acuden en general a lo dispuesto por las Partidas en relación con las distintas formas de señorío:

«Devisa, e solariego, e behetria son tres maneras de Señorio, que an los fijos dalgo en algunos lugares, segund Fuero de Castilla... ${ }^{4}$.

Sin embargo, las interpretaciones que al respecto se hicieron de esta ley fueron dispares. Así, Arce de Otalora propugnaba un concepto verdaderamente amplio de solar conocido, al entender que abarcaba los solares o lugares que los antiguos hidalgos poseían por divisa, solariego o behetría.

«Y assi en montañas, y Vizcaya, y Asturias se llaman solares conocidos las casas antiguas, y principales: porque estas desde su principio y fundación tuuieron algun derecho destos tres, o todos juntos.... $\nu^{5}$.

Por el contrario, García de Saavedra vinculaba el concepto de solar a lo dispuesto por la misma ley de Partida en relación con el señorío solariego.

«...E solariego tanto quiere dezir, como ome, que es poblado en suelo de otro. E este atal puede salir, quando quisiere de la eredad, con todas las cosas muebles, que y ouiere: mas non puede enagenar aquel solar, nin demandar la mejoria que y ouiere fecha: mas deue fincar al señor cuyo es.... ${ }^{6}$.

De esta definición del solariego y de lo dispuesto por el Ordenamiento de Alcalá en relación con esta clase de señorío ${ }^{7}$, Saavedra extrajo la conclusión de que casa de solar no era otra cosa que,

${ }^{4}$ Cfr. Partida IV, título XXV, ley III.

${ }^{5}$ Cfr. Arce de Otalora, J.: Summae nobilitatis hispanicae, et inmunitates Regalium tributorum causas, ius, ordinem, iudicium, \& excusationem breviter complectentis, secunda pars principalis, capít. IV, núm. 7, manejamos la edición incluida en el tomo XVI del Tractatus illustrium in utraque tum pontificii, tum Caesarei iuris facultate iurisconsultum, de dignitate, \& potestate seculari. Ex multis in hoc volumen congesti, additis plurimis, etiam nunquam editis, hac nota designatis \& multó, quam antea, emendationes redditi, Venetiis, MDLXXXIII. En los mismos términos se pronuncia Guardiola, fray J.B. de: Tratado de nobleza y de los títulos, y ditados que oy dia tienen los varones claros y grandes de España, Madrid, por la viuda de Alonso Gómez, MDXCV, cap. XXX, págs. 72 vta. y 73.

${ }^{6}$ Cfr. Partida IV, título XXV, ley III.

${ }^{7}$ Ordenamiento de Alcalá, Título XXXII, leyes XIII -Que fabla del que fuere Sennor de Aldea, ó de Solares, ó oviere Solariego, que non les puedan tomar el Solar-, XXII -Que ha de pagar el fijodalgo que tomare por fuerza alguna cosa del Solariego, é de Abadengo, é de Realengo, é de Behetria-, XXVI -Que ningunt Fijodalgo, nin 
"casa de señor que tiene vasallos solariegos poblados en territorio, y solar de la misma casa ${ }^{8}$.

Esta afirmación parecía estar corroborada por algunos pasajes de las Crónicas de Alfonso XI y Juan II, que permitían inferir la identificación entre solar y vasallaje ${ }^{9}$. La teoría de este autor se fundamenta en esta identificación - «solar es vasallage, y vasallage es solar»-10

Es importante advertir que Saavedra rechazó abiertamente cualquier procedimiento probatorio de la hidalguía al margen de lo establecido por la pragmática de Córdoba. La prueba a través del solar conocido, carecía para él de apoyo jurídico. Pero aun así, era evidente su admisión por los tribunales. Y esta fue la razón que le impulsó a tratar de fijar los elementos que ineludiblemente debían concurrir en las casas para poder ser admitidas como solares. Con este fin, tomando en consideración el pasaje de la Crónica de Juan I sobre las Cortes de Guadalajara y el contencioso ventilado allí entre los hijosdalgo y los prelados del reino en relación con los diezmos ${ }^{11}$, señala los siguientes requisitos o elementos constitutivos del solar: Ser casa fuerte, esto es, contar con cava, tronera y almenas, elementos acreditativos de que en un principio tenían claro carácter militar; estar situada en un determinado espacio geográfico -la Montaña, Galicia, Asturias, Guipúzcoa, Vizcaya y Navarra- y radicada en lugares despoblados y montañosos, por lo que debían considerarse dudosas las emplazadas en pueblos o ciudades; tener armas, voz y apellido del solar; indivisa y transmitida por línea agnada, y, finalmente, que no hubiese sido adquirida por compraventa u otro título particular ${ }^{12}$.

En la concepción de Saavedra, la equiparación entre solar y ejecutoria contenida en la pragmática de Tordesillas ${ }^{13}$, sólo procedía en el caso de concurrir todos y cada uno de los elementos señalados ${ }^{14}$.

otro Sennor no pueda de Solariego tornar Behetria-, XXXII -Como deben pechar la prenda que tomaren en Behetria, é en Abadengo, é en Solariegos-.

${ }^{8}$ Cfr. García de Saavedra, J: Ob. cit., glosa XVIII, núm. 12.

${ }^{9}$ En la primera se decía, por ejemplo, que con la invasión musulmana habían pasado a España moros de grandes solares y en la de Juan II se relataba como en la guerra de Granada le habían acompañado muchos caballeros, entre los que se citaba a Sancho de Leyva, señor del solar de Leyva, Ochoa de Salazar, señor del solar de Salazar, y Diego de Orellana, señor del solar de Orellana, expresiones que para este autor equivalían, respectivamente, a señores de la tierra y vasallos de Leyva, Salazar y Orellana. Vid. García de Saavedra, J.: Ob. cit., glosa XVIII, núms. 12 y 13.

${ }^{10} \mathrm{Ibid}$.

${ }^{11}$ Ibid., núm. 33.

12 Ibid. núms. 33, 34, 35 y 42.

${ }^{13}$ Vid. nota núm. 2.

${ }^{14}$ Vid. García de Saavedra, J.: Ob. cit., glosa XVIII, núm. 12. 
En consecuencia, el hecho de que la casa estuviese habitada por hijosdalgo desde tiempo inmemorial no era suficiente para poder ser calificada como casa solariega ${ }^{15}$.

Juan Gutiérrez sería muy crítico con la posición de este autor. Su teoría se sustenta sobre dos consideraciones:

1. La pragmática de Tordesillas no se refería en ningún momento a la forma de probar el solar conocido, por lo que, a estos efectos, debería considerarse suficiente la acreditación de ser conocida y notoria la nobleza de la persona en cuestión.

2. En materia nobiliaria, el título de solar conocido tenía dos significados. Podía designar, en primer lugar, a todo un territorio. Esto sucedía, por ejemplo, con el infanzonado de Vizcaya, declarado solar conocido de hidalguía por el Fuero y los Acuerdos de las Chancillerías de Valladolid y Granada de 1540 y 1550. Pero, además, descendiendo al plano particular, designaba al solar individualmente considerado, tenido y comúnmente reputado por noble desde tiempo inmemorial ${ }^{16}$.

Lo que Gutiérrez defendía en última instancia, era la interrelación entre los términos de solar conocido y linaje ${ }^{17}$. Partiendo de esta identificación, cobra lógica su concepción de la hidalguía de solar conocido, que entendía referida a quienes descendían de un linaje notoriamente noble,

«...indicado, o mostrado por tal por casa, o solar conocido muy antiguo» ${ }^{18}$.

Su planteamiento chocaba frontalmente con la argumentación realizada por Saavedra. Ninguna de las leyes citadas en apoyo de la identificación entre solar y vasallaje, escapó a la severa crítica del canónigo de Ciudad Rodrigo. La crítica se cierne, en primer lugar, sobre la interpretación de la ley III, título II, de la IV Partida, que, en realidad, se limitaba a distinguir entre las tres formas de señorío, sin identificar en ningún momento su titularidad con la calidad de

15 «...porque si esta consequencia valiesse, avria en Salamanca, Auila, Ciudadrodrigo, Vbeda, y Antequera, y en otras Ciudades infinitas casas de solar, que de tiempo inmemorial son habitadas por hijosdalgo, y por varonia». Cfr. Ibid., núm. 36.

${ }^{16}$ Gutiérrez, J.: Practicarum quaestionum civilium, super quinque prioribus libris primae partis legum Novae Collectionis Regiae Hispaniae, Colonia, Perachon \& Cramer, 1730, libro III, quaestio XVI, núms. 30 y 31.

17 «Lo primero para entendimiento de la materia hemos de presuponer que este vocablo de casa a solar, simpliciter sumpto, es analogo y respectivo al linaje de quien se tracta...». Cfr. Ibid., núm. 30.

${ }^{18}$ Cfr. Ibid., núm. 32. 
hidalgo de solar conocido ${ }^{19}$. Tampoco era acertada la referencia que hacía Saavedra a la ley XXXVII, título IX, de la VI Partida, que al referirse a la manda de solar en testamento, lejos de identificar solar y territorio, permitía entender la equivalencia entre solar y lugar o sitio en el que se edificaba una casa ${ }^{20}$. Más clara le parecía, todavía, la inaplicabilidad al caso de las leyes II, XI, y XIV, título III, del libro VI de la Nueva Recopilación ${ }^{21}$.

Por otra parte, la pragmática de Tordesillas no vinculaba en ningún momento la hidalguía de solar conocido con la tenencia de vasallaje, sino que se limitaba a establecer la equiparación entre el solar conocido y la ejecutoria con posesión actual a los efectos de la exoneración de pechos durante el tiempo de duración del pleito, eliminando de esta forma los abusos que se producían al respecto ${ }^{22}$.

En consecuencia, la actividad probatoria se circunscribía al extremo referente a esta hidalguía, sin entrar en la cuestión de la existencia de vasallaje, elemento que, por otra parte, no concurría en todas las casas solares. De hecho, la práctica forense demostraba que la mayoría de las casas solariegas alegadas y probadas ante las audiencias carecían de dicho elemento ${ }^{23}$. Y por si esto fuera poco, el propio ordenamiento jurídico había consagrado esta diferencia, al tratar por separado de la hidalguía y el señorío de vasallos ${ }^{24}$.

${ }^{19}$ Cfr. Ibid., núm. 118.

20 "...y el solar y casa que después se edifica en el, lo tiene por una misma cosa: pues dize que mandado el solar, se entienda tambien ser mandada la dasa que en el se edifica después, y ansi por esta misma ley parece que se prueva que la significación propria y antigua deste vocablo solar en Espanna, es de suelo y sitio en que se edifica después casa, o otro edificio: y que solar y casa y solar anda todo junto, ...». Cfr. Ibid., núm. 119.

${ }^{21}$ Ibid.

${ }^{22}$ Vid. Nueva Recopilación, libro II, título XI, ley IX -D. Enrique III, en Toro, 1398, y el mismo monarca en Tordesillas, el 14 de abril de 1403.

${ }^{23}$ «...Ergo ita \& eodem modo dicendum est in propósito, quod cum lex Regia ejusque conditor solum expresserit de solar conocido, \& non adjecerit con vasallos: no se ha de entender que estos sean necesarios por curiosas invenciones: porque si la ley lo quisiera, adonde puso y dixo de solar conocido, pusiera con vasallos solariegos: y pues no lo quiso ni requirió sino solamendte de solar conocido: y este se puede verifica propiamente aunque no aya vasallos, y ay muchos solares conocidos sin vasallos, por ninguna via se hazer de dezir ni entender, sea cosa sustancial, ni necesaria tenerlos para el efecto de que tratamos, pues esta qualidad de solar conocido, solamente se requiere por señal indicativa y demostrativa de notoria nobleza, como muchas vezes hemos dicho». Cfr. Gutiérrez, J.: Ob. cit., libro III, quaestio XVI, núm. 48, in fine.

${ }^{24}$ «Si enim idem esset, cur diversis nominibus apellantur, argum. text. in 1. si idem, C. de codicill. Y si fueran una misma cosa no avia para que mandar la ley que fuessen amparados en su libertad y nobleza, durante el pleyto sobre ella: porque los 
La exigencia del vasallaje representaba, finalmente, un grave impedimento para la prueba de la hidalguía solariega de los vizcaínos originarios, que de esta forma verían imposibilitada no solo la prueba de la hidalguía en posesión, debido a la inexistencia de actos positivos distintivos, sino también la de la propiedad, porque en Vizcaya ninguna casa podía acreditar el requisito del vasallaje ${ }^{25}$.

Aun así, el rechazo de este elemento como determinante de la hidalguía solariega, era compatible con el reconocimiento de la preeminencia jerárquica que otorgaba a los solares que lo poseían ${ }^{26}$.

La esencia de la hidalguía de solar no radicaba tampoco en poseer los otros elementos enumerados por Saavedra -ser fuerte, tener torre y armas, y haber permanecido siempre indivisa-. El rechazo hacia estos elementos es igualmente contundente. Carecía de fundamento la exigencia de vínculo o mayorazgo, que en modo alguno podía entenderse determinante de la hidalguía solariega, por no serlo incluso de la propia nobleza ${ }^{27}$. Del mismo modo, el escudo de armas no era un elemento consustancial del solar, sino un elemento puramente incidental ${ }^{28}$.

sennores de vasallos son caballeros y con dignidad noble, según hemos dicho, ni nadie los prendara ni moviera pleyto sobre su hidalguia de solar conocido, pues el mismo solar conocido era el sennorio de vasallos que tienen: y ansi la dicha ley 9. no siruiera de duda contra la naturaleza de las leyes....». Cfr. Ibid., núm. 53.

25 «...Ex quibus ómnibus primo deducitur, que el Fiscal aun en los exemplos que pone en la dicha gloss. 7 n. 25 . de onze casas notoriamente hidalgas de solar conocido, y en que dize concurren las qualidades de todo lo que dixo en la gloss. 18 que ay en Vizcaya dudando por dos vezes, si ay otras semejantes, falta y no esta bien informado de casas de aquel sennorio de Vizcaya: porque en quanto a lo primero en Vizcaya nadie, praeter regem nostrum, tiene vasallos, porque los vizcaínos no reconocen a nadie, salvo al Rey nuestro sennor como a sennor de Vizcaya...y ansi Vizcaya toda seria de hombres buenos labradores, y no auria hijosdalgo en ella ( lo qual nadie jamas ha dicho, sentido, ni apuntado) y quedaria su antigua y notoria nobleza por el suelo, y sus leyes y fueros engannarian, y no serian ciertos...». Cfr. Ibid., núm. 83.

${ }^{26}$ Vid. Ibid., núm. 53.

27 «...nullo ergo modo potest affirmari que la causa del mayorazgo o vinculo solos de porsi, o juntos constituyeran, seguir seia que el posseedor se haria noble, aunque no fuesse descendiente de noble linage: loqual es falso evidentemente: y tambien valdria la consequencia, Vendiose la dicha casa, ergo no era casa y solar de hijosdalgo, lo qual no es ansi...». Cfr. Ibid., núm. 102.

28 «Praeterea, el poner en tales casas y solares conocidos de notorios hijosdalgo unas otras armas, es a par de nombre o sobre nombre de cada uno. Los quales, y ansi las armas, sirven solo de conocer y diferenciar se los unos hombres y linajes de otros, porque para solo esto fueron inventados...Y ansi como el nombre que me pongo no me constituye mi esencia,... ni esta essencia consiste en la nominacion del sobre escrito, o tratamiento de las personas con que converso, porque esto no muda ni perjudica a la verdad...desta misma suerte las armas e insignias de cada uno, no alteran ni pueden trocar o cambiar su essencia natural e intrinseca de la sangre, ni le puede 
Por último, la delimitación de los espacios geográficos en los que Saavedra situaba los solares, era contradicha por las resoluciones judiciales que diariamente admitían su existencia en lugares diferentes ${ }^{29}$.

Puede decirse, entonces, que todos y cada uno de los elementos que el fiscal de la Chancillería vallisoletana consideraba consustanciales al solar, adquirían en la exposición de Gutiérrez un carácter meramente accesorio ${ }^{30}$.

\section{LA PRUEBA DE LA HIDALGUÍA DE SOLAR COMO UN PROCEDIMIENTO ALTERNATIVO PARA OBTENER EL RECONOCIMIENTO DE LA HIDALGUÍA EN PROPIEDAD}

Ante el silencio de la pragmática de Tordesillas sobre lo que debía entenderse por hidalgo de solar conocido, Gutiérrez destacaría la importancia que en esta cuestión tenían la costumbre inmemorial y la práctica comúnmente observada ${ }^{31}$. Este planteamiento le conduce a defender la prueba de la hidalguía solariega a través de la común e inmemorial reputación entre los vecinos del lugar, sin la concurren-

calificar o menguar el deudo, o sangre, ni le puede calificar o menguar el deudo, parentesco, o sangre que tiene...De manera que conforme a lo dicho, el no tener armas e insignias esculpidas en la casa principal de solar de hidalguia no contradize a su esencia, y solo la casa vinculada y fuerte de porsi, y las insignias o escudos de sus paredes de por si, no son bastantes a dar nobleza, ni aun todo esto junto la induze...». Cfr. Ibid., núms. 105, 106, 107 y 110, in fine.

${ }^{29}$ "...y conforme a lo dicho y su razon tambien en tierra llana puede aver y ay casas de solar conocido, y assi se admiten los tribunales donde se trata de las causas de los hijosdalgo...».Cfr. Ibid., núm. 123.

${ }^{30}$ «...Y siendo este solar y casa en que ella esta, conocido de hijosdalgo notorios, esto es lo que basta, y con que se contenta la ley, que no requiere otra cosa: y esta es qualidad indicativa de notoria nobleza, y como quiera que por ella se demuestre sin solariego, ni otro sitio, no ay que pedir lo que la ley no pidio, ni obligar a mas de lo que ella requiere, pues se funda solamente en notoria nobleza, y para indicacion y provanza della requiere solamente el solar conocido de notorios hijosdalgo, sino (y no) lo demas que el fiscal piensa, y procura nuevamente introducir». Cfr., Ibid., núm. 69, in fine.

31 «Y ansi nuestra ley real, pues habla de hijosdalgo de solar conocido, sin declarar mas, bien presupone aver costumbre en esto para saber qual se llame solar conocido, y a ella parece se remita: y esto ay declarado qual sea en otras causas semejantes, conforme a lo sobredicho: luego no ay para que dudar dello, ni inventar, ni requerir otras cosas que la ley, ni la costumbre requiere: sino estar la practica e interpretacion comun de los sabios, que es la de los dichos tribunales, que en esto se ha guardado y guarda siempre: por la qual se ha de presumir y juzgar per supra dicta». Cfr. Ibid., núms. 78 y 79. 
cia de otros elementos, a excepción de aquellos lugares en los que estuviesen exigidos por ley o por costumbre ${ }^{32}$.

La admisibilidad de esta vía de prueba estaba refrendada no sólo por esta pragmática, sino también, por la ley II, título XXI, II Partida. Admisibilidad que Arce de Otalora defendía incluso en los casos en que el litigante no podía demostrar la posesión del padre, o cuando había sido vencido con anterioridad en el juicio posesorio ${ }^{33}$.

Este planteamiento encontraba apoyo definitivo en el proemio de la pragmática de Córdoba, que proclamaba que su objetivo no era otro que el de resolver la problemática generada por la interpretación heterodoxa y reiterada de la ley de Juan I de 7 de noviembre de $1389^{34}$, reguladora de los extremos que debían probar los hijosdalgo al objeto de no ser inquietados en el goce de sus privilegios ${ }^{35}$.

32 «De todo lo qual resulta, que para la esencia y sustancia de la hidalguía por via de solar conocido, no se requiere torre ni casa fuerte, ni cava ni troneras, ni individualidad de bienes: salvo si en la comarca y lugar de los solares conocidos donde ellos estan sitos, alguna ley o costumbre lo requiriesse en parte o en todo: porque como hemos dicho, aquel es solar conocido de hidalguia, el que tiene los requisitos necessarios, conforme al comun entendimiento y reputacion de los vecinos y naturales de su comarca...». Cfr. Ibid., núm. 103. E insiste más adelante en que: "Nunc deveniamus ad modum \& praxin probandi nobilitatem, por via de solar conocido, o casa conocido de hidalguia: \& primo dicendum, que aquel es solar conocido de hijosdalgo notorios, o de caballeros respective, que se prueba que es avido y tenido, y comúnmente reputado por tal en la provincia y comarca do esta sito, y que dello es ansi la publica voz y fama de tiempo inmemorial a esta parte sin contradicion alguna ...» Cfr. Ibid., núms. 129 y 130.

${ }^{33}$ Cita en apoyo de su tesis la II Partida, título XXI, ley III -«Ca pues que el linaje faze que la ayan -la hidalguía- los omes asi como herencia»-.Cfr. Arce de Otalora, J.: Ob. cit., tertia pars principalis, cap. VI, núm . 7, in fine.

${ }^{34}$ Aunque en la nota marginal de esta ley se menciona como su fecha la de 7 de noviembre de 1384 , lo cierto es que de su texto se infiere que data del año 1389, por cuanto en su parte final alude al servicio concedido por los reinos «este año que agora passó de 1388». Nueva Recopilación, libro II, título XI, ley VII.

35 «Porque somos informados que los Lugarestenientes de los Alcaldes Hijosdalgo, y Notarios de las Provincias...han dado muchas sentencias en que han pronunciado, que al que se dezia que estaua en possession de hijodalgo, le han mandado guardar la possession en que estaua de Hijodalgo, para que no fuesse empadronado, ni prendado, ni pechasse, ni contribuyesse en los pechos reales, ni Concejales, ni en las otras contribuciones en que los hijosdalgo no son tenudos de pechar y contribuir..., en lo qual diz que nos auemos recibido mucho deseruicio y diminucion en los pechos y derechos a nos deuidos, y los dichos Concejos que ansi han litigado, han recibido mucho agrauio y daño, y se quexan nuestro procurador fiscal, y los procuradores de los dichos Concejos, diziendo...y so color de una pragmatica que el Rey don Juan nuestro visabuelo hizo en Leon, que es la ley 7 supra proxima, diz que interpretando la dicha ley siniestra, e injustamente, y en menoscabo, y detrimento de los pechos, y derechos a nos deuidos, y en agrauio, y daño de los dichos Concejos, quando hallan posesión prouada de veinte años, quier sea de su padre solamente, o de su abuelo, luego pronuncian los dichos 
La pragmática de Córdoba había venido, así, a novar el procedimiento probatorio establecido por aquella ley, denunciando los abusos cometidos y declarando la insuficiencia de la prueba de la posesión limitada al padre y al abuelo del litigante. Sin embargo, nada permitía concluir que ambas leyes persiguieran obstaculizar el reconocimiento y la declaración de hidalguía a quienes fuese imposible acreditar la posesión. Por esta razón, junto a los procedimientos orientados a obtener la declaración de hidalguía en propiedad posesoria o en mera posesión, era preciso admitir la declaración de la propiedad a través de la prueba del solar conocido ${ }^{36}$.

El litigante tendría que probar la existencia del solar -para lo que era suficiente su reputación inmemorial entre los vecinos del lugar- ${ }^{37}$ y descender, bien directamente de sus titulares por línea agnaticia, bien de sus parientes colaterales consanguíneos. Esta era la opinión doctrinal favorable a la admisión de esta vía de prueba, que se basaba en el principio de que el juicio sobre la propiedad absorbía al juicio sobre la posesión ${ }^{38}$.

Alcaldes, y Notarios de las Prouincias sobre el possessorio, mandando guardar al que se dize Hijodalgo la possession de hidalguia...y ansi mismo no han mirado, que aunque la dicha pragmatica contenga justicia; pero claramente dispone, que quando los que contienden estan en possession de padre y abuelo por veynte annos, que se entiende, quando su padre y abuelo vivieron en aquel mismo lugar, o en su comarca...se requiere que aya provanza de todas tres personas, conviene a saber del que contiende, y su padre, y de su abuelo, y que la possession destos padres, y abuelo sea de veinte años, siendo todavía el actor tenudo a prouar su demanda en lo tocante a su persona...». Cfr. Nueva Recopilación, libro II, título XI, ley VIII, -Don Fernando y Doña Isabel, en Córdoba, a 10 de mayo de 1492, pragmática-, proemio.

36 «Pero no por esto fue la intención in mente de los legisladores querer quitar, ni quitaron la provanza de hidalguia de solar conocido, de que habla la ley del Rey don Enrique el tercero, ni hablaron della, ni en esto innovaron cosa alguna, sino solamente en lo que esta dicho, que es de lo que se tratta en el proemio de la misma ley, y no otra cosa, por el qual se toma luz y entendimiento para toda ella: y aunque en la demostrativa que pone la misma prematica de Cordova para prova la hidalguia, no se acordasse (siendo mas nueva ley, de los hijosdalgo de solar conocido: pero como quiera, que aunque no trate dellos, esta sea forma provatoria no fue visto excluyer otras provanzas semejantes y mas bastantes, como son las de solar conocido y de executoria con posesión, de que habla la ley siguiente, a quien no corrige la nuestra, antes estas se han de admitir, como esta dicho...». Cfr. Gutiérrez, J.: Ob. cit, libro III, quaestio XV, núm. 43. Vid. también Arce de Otalora, J.: Ob. cit., tertia pars principalis, cap. VI, núm. 9.

${ }^{37}$ Gutiérrez, J. : Ob. cit., libro III, quaestio XVI, núms. 130 a 139.

38 "Quis enim dubidat, (que si yo probasse ser descendiente legitimo de la boz de Lara, o de una de las casas de los grandes de Castilla, y lo aueriguasse bastantemente por testigos, y escripturas muy antiguas y Authenticas, que aunque non probasse posesión, y reputación de mi padre, ni abuelo. Immo se probasse, que hauia pechado, porque por ventura por flaqueza, o pobreza, o descuydo cayeron de su possession, y reputación, y se dexaron empadronar, y repartir constando de mi solar y nobleza bastantemente, sino que me declararian por hijodalgo en propiedad hauiendo yo 
Por consiguiente, esta cuestión generó dos posturas antagónicas e irreconciliables. La que podemos calificar como concepción purista, no admitía más procedimientos probatorios de la hidalguía que los establecidos por la pragmática de Córdoba de 1492. Frente a ella, una interpretación más abierta e integradora, trataba de dar solución al problema de la indefensión que podía generar su aplicación estricta a quien no podía acreditar la posesión del padre o del abuelo, o de ambos, pero si que el abuelo o el bisabuelo, o un ascendiente en grado más remoto por línea agnada, procedían de un solar conocido. El reconocimiento de este medio de prueba podía favorecer incluso a quien había sido vencido con anterioridad en un juicio posesorio.

\section{LA CALIFICACIÓN DE LA «HIDALGUÍA DE SOLAR» EN LOS PADRONES DE LA MONEDA FORERA. REPERCUSIONES}

Aquí radicaba la importancia en el plano jurídico de la inclusión con la calificación de «hijodalgo de solar conocido» en los padrones de la moneda forera y del servicio ordinario. Tratándose de documentos jurídicos dotados de valor probatorio para determinar, tanto los sujetos pasivos y las cantidades a percibir de cada uno por la Real Hacienda, como los sujetos no obligados al pago, la calificación a la que nos venimos refiriendo no podía ser meramente aleatoria, ni tener como único objetivo la proclamación de un rango jerárquico superior -que también- al resto de los exentos tributarios. Máxime, cuando la ley determinaba con carácter excluyente los términos que deberían emplearse en la elaboración de aquellos padrones -«al hidalgo por hidalgo, y al Clerigo por Clerigo, y al pechero por pechero: y al quantioso por cierto»-. Cualquier término añadido representaba una conculcación de la norma ${ }^{39}$.

A pesar de la claridad del mandato legal, la revisión de los padrones revela la convivencia de este mandato con los usos tradicionalmente observados. Este fenómeno, comprobable en todos los territorios de la Corona de Castilla, lo es aun con mayor rigor en los más

deduzido el petitorio enjuyzio: pues aunque; me tengan probado, y vencido en la posesión,) iudicium proprietatis (de qua constat) absorbet iudicium poss...». Cfr. Arce de Otalora, J.: Ob. cit., tertia pars principalis, cap.VI, núm. 7, in fine.

39 «Tenemos por bien, que los empadronadores y fazedores de los padrones de la dicha moneda empadronen por calle ahita a todas y qualesquier personas q huuiere en el lugar y collacion do fuere empadronador, nombrando por nombre, al hidalgo por hidalgo, y al Clerigo por Clerigo, y al pechero por pechero: $\mathrm{y}$ al quantioso por cierto, y al que no huuiere quantia, que lo pongan por no contioso... ". Cfr. Nueva Recopilación, libro IX, título XXXIII, ley X. 
septentrionales, donde los padrones son especialmente ricos en las calificaciones nobiliarias, esto es, aquellos adjetivos o aditamentos que acompañaban al único término consagrado por la ley. Al lado de las que destacaban la común aceptación e indiscutible reconocimiento de la hidalguía -hidalgo notorio- o el origen de la nobleza del empadronado -hidalgo de sangre o de privilegio-, y aquellas que reflejaban el alcance de la sentencia ganada en juicio contradictorio -declarando al hidalgo en propiedad o en mera posesión-, así como el hecho de haber obtenido la correspondiente ejecutoria, aparecen las calificaciones que aludían a la procedencia de un solar conocido, con frecuencia ligadas a las de devengar quinientos sueldos y a la de armas poner y pintar ${ }^{40}$.

La inclusión del hidalgo con la calificación de "solar conocido», llevaba aparejadas dos importantes consecuencias. En el plano jurídico, abría la posibilidad de que su descendencia tuviese a su disposición un importante medio de prueba sobre la procedencia de un solar conocido de notorios hijosdalgo. Algo realmente útil, cuando con el devenir del tiempo y por circunstancias sobrevenidas, resultara imposible probar en juicio contradictorio, con arreglo a las prescripciones de la pragmática de Córdoba de 1492, todos y cada uno de los extremos exigidos para obtener su declaración en propiedad o en posesión.

40 Sobre la calificación de la hidalguía como de «devengar quinientos sueldos»existen diversas teorías. Al margen de las que carecen de refrendo jurídico, con arreglo a lo establecido en la Ley II, Título X, Libro VIII de la Nueva Recopilación, García de Saavedra vinculó el origen del término a la suma pecuniaria con que los hidalgos satisfacían las injurias por ellos causadas. Sin embargo, esta calificación gozaba de mayor antigüedad, como lo acreditan las Leyes LXXXV y CXXXI de Estilo, al determinar que la pena por deshonrar a un hidalgo era de quinientos sueldos, suma que el ofensor venía obligado a satisfacerle. Aquí radicaba el origen del término para Arce de Otalora, con el que se muestra conforme Moreno de Vargas. Vid. . Nueva Recopilación, Libro VIII, Título X, Ley II. García de Saavedra, J: Tractatus de Hispanorum nobilitate..., glosa I, núm. 11. Arce de Otalora, J.: Summae nobilitatis hispanicae, ... , secunda pars principalis, cap. IV, núms. 11 y 12. Moreno de Vargas, B.: Discursos de la nobleza..., discurso V, núm. 16. La calificación de «hidalgos de armas poner y pintar» aludía a los que pertenecían a un linaje poseedor de escudo de armas conocido. Pero el uso de armas propias del linaje no era un elemento esencial de la hidalguía, ni siquiera de la solariega. De forma especial, al referirse a ésta, Juan Gutiérrez insistió a la hora de destacar su carácter de signos o manifestaciones de la nobleza, pero no elementos esenciales. Y esto parece haber sido así por dos razones: porque existían nobles que carecían de armas conocidas y porque el uso de escudo de armas, contrariamente a lo que en principio podría suponerse, no correspondía en exclusiva a la nobleza, sino que también podían hacer uso de ellas los plebeyos, con la única limitación de no utilizar las que pertenecían a familias nobles, tal y como resolvieron, entre otros autores, Bártolo y Baldo. Gutiérrez, J. : Practicarum quaestionum civilium... Libro III, quaestio XVI, núms.. 106 y 107. Moreno de Vargas, B.: Ob. cit., discurso XVIII, especialmente. núms. 1 y 6. 
Pero al mismo tiempo, en el plano social, reflejaba la existencia de un orden interno jerárquico dentro del estamento nobiliario local.

Creemos que nos movemos en un ámbito donde la fuerza de los usos de carácter local, fuertemente arraigados, especialmente en los territorios más septentrionales, donde la nobleza era mayoritaria o muy numerosa, lograron pervivir frente a un mandato legal que les era adverso.

Creemos también, que ambas razones a las que aludimos, justificaron, tanto la oposición de los hijosdalgo de solar conocido a ser incluidos en un padrón de la moneda forera o del servicio ordinario con omisión de esta calificación, como la del concejo a empadronarlos con ella cuando no era la que realmente les correspondía.

Un buen ejemplo del aditamento de calificaciones, supuesta o realmente inmerecidas, lo encontramos en el concejo de Tineo. En 1678, a petición del fiscal, la Sala de Hijosdalgo de la Real Chancillería de Valladolid recababa la remisión de los padrones del año 1674, bajo sospecha de irregularidades, tanto en el señalamiento de estado conocido, como en el de calificar "hidalguías de casa solar conocido y de armas poner y pintar ${ }^{41}$. Según resulta del tenor del documento, el problema, lejos de afectar exclusivamente a las personas que aparecían relacionadas al principio, afectaba a otras muchas procedentes de un mismo tronco, por lo que se había instado a la Sala a la realización de una investigación exhaustiva ${ }^{42}$.

Se vieron involucrados varios hidalgos de calidad notoria -si bien la notoriedad de la hidalguía no estaba en discusión-, como D. Diego Caballero Flórez y D. Juan de Bustiello Pambley ${ }^{43}$. La oposición del común a lo que se había consignado en sus correspondientes asientos era contundente. En relación con el primero, se dice,

${ }^{41}$ ARCHV, Protocolos y Padrones, Caja 144/26.

42 «Y tambien tienen las familias que en este papel sean puesto otras muchas que les toca el mismo defecto y poniendo las cavezas y los que se quieren hacer tronco de suyo estan puestas las ramas...Y otras diferentes personas están puestas en dicho padron que tendran defectos y por no los alcançar ni conoçer quien da esta quenta no los pone pero quando se viniere a la averiguaçion de lo uno se averiguara todo y lo que no supieren los unos lo sabran los otros...» Cfr. Ibid.

43 «...Y en quanto las familias que quedan referidas se ponen de cassas solariegas sin serlo solo se les pone ese defecto de que se ponen de cassa solar conoçido de armas poner y pintar porque no les tocan por baronia y si algunos las tienen es por hembra que es lo mismo que si no las tubieran que en lo de ser hidalgos notorios no se les pone o bien porque estan puestos assi en los padrones de padres y abuelos...». Cfr. Ibid. 
«...a este le an puesto la añadiçion de ser señor de la cassa de los Cavalleros con ser anssi que el mismo su padre ni abuelo ni antecessor ninguno no se le an puesto esta addiçion porque tal cassa no se conoçe la aya en este pais de Tineo ni que pinte armas ni las tenga ni hubo escudo de armas en su cassa asta ahora que lo pusso y aun con ponerlo el mismo no pusso las del apellido de caballero sino las de su madre y abuela y muger que aunque ay apellido de Cavalleros no ay cassa ni armas del en dicho Concejo sino que lo tomaron por fantasia y el juez y el empadronador ydalgo son primos hermanos de dicho D. Diego Caballero Florez y por esso le pusieron dicha adiçion por lo qual deben ser castigados ${ }^{44}$.

En cuanto a D. Juan de Bustiello, se advierte que carecía de armas por línea de varón, y que sólo las tenía por línea materna,

«...por ser de la casa de Pambley y no espermitido quando no les toca por varonia, el ponérselas sino es que vengan a ser señores de las cassas por donde les tocan poner armas que en tal casso las pueden poner y de otro modo no, si no es que las tengan por baronia ${ }^{45}$.

Al menos en el primer caso, la oposición fue ratificada a raíz de la aportación de un traslado de cierto memorial, que había sido elaborado a instancia de un miembro de la familia con ocasión de un pleito sobre la tenencia de la vara de alguacil mayor de aquel concejo. Las declaraciones testificales que obraban en la información de referencia, confirmaban el parentesco de consanguinidad del pretendiente con D. Diego Caballero, al que identificaban no sólo como señor de la casa solar de los Caballero, sino también de la de los Pertierras, sita en la propia villa de Tineo, y de la de Fontaniella, afirmaciones que fueron rotundamente desmentidas por la parte contraria ${ }^{46}$.

En otros casos, eran los propios hidalgos los que se enfrentaban al concejo para conseguir ser asentados con la calificación a la que creían tener derecho. En 1672, el fiscal de la Real Chancillería se querellaba contra los diligencieros de Esponzúes, en el valle de Toranzo, obispado de Santander, por supuesto falseamiento de padrones. En el interrogatorio a que fue sometido el empadronador el 23 de junio de 1673, declaró haber obrado siempre de buena $\mathrm{fe}^{47}$.

${ }^{44}$ Cfr. Ibid.

${ }^{45}$ Cfr. Ibid.

${ }^{46}$ Se insiste en negar no sólo la existencia de la casa solar de los Caballero, sino también de la de Fontaniella, y de la titularidad sobre la de Pertierra, que no dejaba de ser una simple pretensión pendiente de litigio. Ibid.

47 «...y aunque en los padrones antecedentes que se entregaron al confesante 
Aunque el encausado negó siempre las falsificaciones que se le imputaban y haberse ajustado en todo a lo que resultaba de los padrones de años anteriores, las declaraciones testificales obraban claramente en su contra, por lo que el fiscal solicitó su ingreso en prisión hasta el momento de recibir la correspondiente sanción y el embargo de sus bienes ${ }^{48}$.

Las catas documentales que se han realizado, ponen de manifiesto que la utilización de las calificaciones examinadas, responden a usos de carácter local, razón por la que aun siendo abundantes en los territorios indicados, nunca llegaron a ser universales. Así, en el padrón elaborado en la jurisdicción de Ribadesella el año 1686, para la recudación de la moneda forera que correspondía al año 1687, no se hacía constar sino la condición hidalga, con señalamiento de los sujetos que tenían pleito pendiente en la Sala de Hijosdalgo de la Real Chancillería de Valladolid ${ }^{49}$. Lo mismo sucedía en el padrón elaborado por la Villa de Santillana del Mar y su jurisdicción para la recaudación de la moneda forera correspondiente al año $1616^{50}$. En los de la Junta de las Siete Villas de los años 1677 a 1689, remitidos este último año a la Sala de Hijosdalgo, a instancia del fiscal, en relación con la introducción al estado noble de vecinos del estado general, únicamente se diferenciaba entre hidalgos e hidalgos notorios $^{51}$ y en el de la Hermandad de Valdeolea, jurisdicción de la villa de Reinosa, del año 1620, las únicas calificaciones que encontramos son a hidalgos de privilegio y de ejecutoria, sin alusión alguna a hidalgos solariegos, ni de armas poner y pintar ${ }^{52}$.

No creemos que la falta de referencias a hidalgos de solar conocido, por demás abundantes en el Principado y en la Montaña, obedezca a su ausencia de hecho, sino a una adecuación más estricta a la ley y a lo preceptuado por las provisiones reales para la elaboración de los padrones ${ }^{53}$.

para hacer el sobre que es este pleito esta puesto con el aditamento de hijodalgo el confessante no hizo reparo en ello, porque le pareció que lo mismo era ponerle por hijodalgo que por hidalgo por tener uno y otro de igual calidad». Cfr. ARCHV, Protocolos y Padrones, 1978/2.

${ }^{48}$ Ibid.

${ }^{49}$ ARCHV, Sala de Hijosdalgo, 7/20.

${ }^{50}$ ARCHV, Protocolos y Padrones, 38/1.

${ }^{51}$ ARCHV, Sala de Hijosdalgo, 1992/4.

${ }^{52}$ ARCHV, Protocolos y Padrones, 19/28.

${ }^{53}$ En la de fecha 15 de julio de 1615 dirigida a la jurisdicción de Santillana del Mar para la recaudación de la moneda forera correspondiente a 1616 -el texto consignaba por error como fecha tope para la confección del padrón, el último día de febrero de 1614, cuando en realidad se refiere a 1616-, se repetía el mandato legal en los si- 
Algo semejante sucedía en alguno de los Concejos situados al norte de Burgos. En el lugar de Huérmeces, integrado en la cuadrilla de Santibáñez, no se encuentran más calificaciones que las que designan a los caballeros de hábito de las Órdenes Militares, el resto de los vecinos son designados como hidalgos notorios -la inmensa mayoría- o pecheros, aunque existen excepciones como la de algún que otro hidalgo en posesión, o la de los vecinos asentados como dudosos o pendientes de que la Real Chancillería les diese estado conocido ${ }^{54}$.

Más al sur, en Olmedo, el padrón elaborado en 1662, aunque integrado por dos cuerpos, uno en el que se consignaron los asientos del estado general y otro para el estado noble, las calificaciones existentes en este último se ajustaban estrictamente a lo establecido por la ley, de manera que no se distinguía sino entre clérigos, hidalgos y exentos, indicando, en relación con estos últimos, si la exención lo era por gozar de un privilegio -libertados-, por tratarse de sujetos recien casados o por tener seis hijos varones vivos, incluyendo, en su caso, al servicio doméstico y las cantidades que correspondían a las personas que prestaban este servicio ${ }^{55}$.

En realidad, la inclusión de la calificación de «solar conocido», si bien representaba cierto relajamiento en la aplicación estricta del mandato contenido en la Ley X, título XXXIII, libro IX de la Nueva Recopilación, nada añadía a la situación fiscal privilegiada del hidalgo, por lo que no representaba detrimento para la Real Hacienda. Tal vez por esta razón, los fiscales de la Chancillería vallisoletana se mostraron más tolerantes con la inclusión en los padrones de esta y otras calificaciones, que con los supuestos en los que peligraba la integridad de los derechos de la Corona.

Las reclamaciones de los hidalgos a los que se trataba de privar de esta calificación, se dirigen a obtener el reconocimiento o man-

guientes términos: «... y fiel y verdaderamente empadronaran todos los vecinos de esa dicha ciudad, y lugares, escribiéndolos a calle hita poniendo el Clerigo por Clerigo y el hidalgo por hidalgo, y pechero por pechero, y a las viudas, y huérfanos, y mozos asoldadados, y nombrando al cuantioso por cuantioso sin encubrir cosa alguna, y el abono del quantioso sea que tenga de hazienda la cantidad contenida en el quaderno de la dicha moneda forera, según, y de la manera que se acostumbro, y devyo hazer los años pass, los quales dichos empadronadores sean obligados a tener hechos y cabados todos los dichos padrones, hasta fin del mes de febrero del dicho año venidero, de mil y seiscientos y catorce...». Cfr. ARCHV, Protocolos y Padrones, 38/1.

${ }^{54}$ Padrones de 1680 y 1687, aportados a un pleito entre el estado de los hijosdalgo y el de los hombres buenos de dicho lugar sobre mitad de oficios de república. ARCHV, Pleitos Civiles, Moreno (F), C. 2618/5.

${ }^{55}$ ARCHV, Protocolos y Padrones, 13/1 y 13/7. 
tenimiento de esa particular consideración en documento público, que garantizaba la transmisión del conocimiento del solar a la descendencia -con los beneficios jurídicos que hemos apuntado-, al tiempo que los situaba, ya desde una perspectiva social, en un lugar preeminente dentro del estamento nobiliario local.

Nuevamente nos encontramos aquí con ciertos usos que lograron convivir con el mandato legal. La ley a que nos referimos ordenaba que la elaboración de los padrones se efectuara a "calle hita», esto es, barrio a barrio y calle por calle. Pero este mandato no parece haber sido obstáculo para que en muchos concejos, se siguiera un determinado orden, que parece obedecer a factores como la preeminencia social que daba el hecho de ser dueño o descender de un solar conocido.

Podrían traerse aquí un prolijo número de ejemplos, pero será suficiente recoger alguno de los más representativos. En el concejo de Castropol, donde la mayoría de los vecinos pertenecían al estado noble, los padrones son fiel reflejo de lo expuesto. El orden seguido en la elaboración del correspondiente a la capital del concejo a lo largo del el siglo XVII parece ajustarse al modelo descrito. Calle por calle, se suceden, primeramente, las referencias a los solares más importantes: Lantoira, Villaamil, Andrade, Aguiar, Presno, Donlebún, Lago y Baamonde, VillarMontenegro, Trelles, Valdepares y otros muchos, para ir dejando paso a los hidalgos notorios y a los que figuran sin ninguna calificación ${ }^{56}$.

Este orden, constatable en la capital del concejo, lo es también, si cabe con mayor claridad, en sus diferentes parroquias. En la de Coaña, los padrones recojen en los primeros asientos a miembros de los solares de Infanzón y Montaña de Ruinegro, Sierra, Rua, etc. En los de la parroquia de Seares, la preeminencia corresponde a los de Lantoira, Moldes, Castro, Lamas, Lavega, Santo Andrés, Santiso y otros, asentando a continuación a los hidalgos a los que no se atribuye un solar conocido ${ }^{57}$.

Lo mismo sucedía en algunos concejos del interior del principado. En los padrones de Tineo del año 1657, aparece en primer lugar D. Francisco Osorio Maldonado y Tineo -en los padrones posteriores figura con los apellidos de Maldonado, Laciana, Mendaña y Tineo-, señor y mayorazgo de la casa de Tineo y de la de Priaranza y sus jurisdicciones, calificado como hijodalgo notorio de armas poner y pintar. A continuación obran veinticuatro asientos correspondientes

${ }^{56}$ Pueden servir de ejemplo los padrones de la villa de los años 1638, 1644 y 1650. AAV, Fondos del Concejo de Castropol, Sección Padrones, Caja 00899 -Tomo VII-.

${ }^{57}$ Ibid. 
a otros hidalgos con esta última calificación. A partir de este punto, los asientos se limitaban a consignar la condición de hidalgo o pechero. El seguimiento de este orden se ve confirmado en los padrones de 1662, 1669, $1674^{58}$.

Aunque en el reino de Galicia la nobleza era minoritaria, en los territorios donde si era particularmente numerosa, como en las comarcas montañosas situadas al este de la provincia de Lugo, si bien los padrones suelen entremezclar los vecinos de uno y otro estamento ${ }^{59}$, las calificaciones para los vecinos del estado noble aluden también a solares conocidos -abundantes en este ámbito geográfico-, a la calidad notoria, la de carta ejecutoria y a la simple posesión.

No se han localizado padrones del siglo XVII, pero si de los primeros años del siglo XVIII que refrendan esta afirmación. En el correspondiente al año 1702, este es el criterio que preside, por ejemplo, los elaborados en la jurisdicción de Penamayor, el coto de Córneas, la jurisdicción de Cancelada de Abajo y los concejos de Cervantes y Navia de Suarna. En este último, sólo en la feligresía de Santiago de Gallegos, de un total de cuarenta y tres vecinos, tres eran hidalgos de casa solar conocido, dos notorios y trece de ejecutoria ${ }^{60}$. En el partido de Vilarpandín, perteneciente al mismo concejo, figuran asentados ocho hidalgos de casa y solar conocido, con sus correspondientes hijos, otros cuatro reciben la misma calificación, aunque no se identifica su solar y, finalmente, el número de hidalgos de ejecutoria asciende a treinta y siete ${ }^{61}$.

Son numerosas las referencias alusivas a solares muy calificados como los de Donís, Murias, Vilachá, Vilarpandín y Lamas de Moreira, especialmente a estos dos últimos ${ }^{62}$.

${ }^{58}$ ARCHV, Protocolos y Padrones, Caja 144/26.

${ }^{59}$ Solo en algún concejo donde la nobleza era realmente minoritaria, la encontramos a la cabeza del padrón sin solución de continuidad y, a continuación, los asientos correspondientes a los vecinos del estado llano. Constituye un buen ejemplo el padrón del concejo de Sarria, en el obispado de Lugo. AHPL, Sección Secretaría, Subsección Estadística, Serie Padrones, 00408/00, folios 776 y sigs.

${ }^{60} \mathrm{Ibid}$., folios 1226 vto a 1227 vto.

${ }^{61} \mathrm{Ibid}$., folios 1237 vto. y 1238 vto.

${ }^{62}$ En el concejo de Navia de Suarna, descendían del de Lamas, entre otros, D.Diego Becerra y Lamas, y sus hijos, D. Felipe y D. Pedro, vecinos del lugar de Gallegos, feligresía de Santiago de Gallegos; D. Antonio Becerra, vecino del lugar de Villarquide, en la misma parroquia; D. Diego Gómez de Ulloa, del lugar de Lencias, feligresía de Santiago de Castañedo; D. Antonio Lamas y Balboa, del lugar de Villarguende, feligresía de Santiago de Queizán, así como los Losada Lamas, señores de la casa de Queizán; D. Antonio Teijeiro y Lamas y sus hijos, vecinos de Santa Marina de Ribón; D. Gaspar Gómez de Navia y Lamas y Doña Isabel de Villaver y Quiroga, 
Las calificaciones de "solar conocido» eran igualmente numerosas en los padrones del concejo de Cervantes ${ }^{63}$, así como en el valle de Cancelada $^{64}$. Sólo en la pequeña feligresía de Quintá, perteneciente a la Jurisdicción de Cancelada de Abajo, fueron reconocidos como hidalgos solariegos, D. Gonzalo Becerra y don Pedro Bolaño Rivadeneyra ${ }^{65}$.

Desde la supresión de la moneda forera en virtud de Real Cédula de 22 de enero de 1724, y con ella de los padrones para su repartimiento, serían los padrones de distinción de estados los que tendrían la misión de reflejar la estructura estamental de la sociedad, con distinción entre nobles y estado general. Estos padrones permiten constatar la pervivencia de los usos a que nos referimos en los lugares en que se habían venido observando tradicionalmente.

Su arraigo debió ser tan firme, que aun después de lo dispuesto por Auto de 6 de mayo de 1786 en que se prohibían las expresiones voluntarias, se continuaron utilizando las calificaciones. Su flagrante incumplimiento motivaría algunas Reales Provisiones de la Real Chancillería de Valladolid, como la de fecha 10 de marzo de 1791, que contenía un Real Auto que ordenaba despachar Real Provisión

vecinos del lugar de Vilarpandín, en el partido del mismo nombre; D. Luis Pardo de Andrade y Lamas -dueño de la jurisdicción y casa de Perdigueira, sita en el concejo de Ibias, principado de Asturias- y sus hijos, así como D. García Mendez de Navia y Lamas, vecinos todos del lugar de Virigo, en el citado partido de Vilarpandín. Ibid., folios 1226 a 1227 vto., 1228, 1231 a 1233 vto., y 1237 a 1238 vto. También descendía de este solar D. Bernardo Osorio y Lamas, dueño del palacio de Arriba o de Eirexe, en Santiago de Galegos, concejo de Navia y vecino del lugar de Riodarco, coto de Penamayor, donde fue empadronado con esta calidad. Ibid., folios 698 y sigs. Sobre este palacio vid. García-Gabilán Sangil, J.: «Historia de un palacio de la montaña luguesa: El palacio de Arriba de Santiago de Gallegos, en Navia de Suarna», en Xúbilo, núm 11, noviembre de 1999, págs. 36 a 38.

${ }^{63}$ AHPL, Sección Secretaría, Subsección Estadística, Serie Padrones, 0408/00, folios 1194 y sigs.

${ }^{64} \mathrm{Ibid}$., folios 1158 y sigs.

${ }^{65}$ «...= Don Gonzalo Vecerra de Navia y Lamas y mas hijos legítimos que fincaron de Gonzalo Becerra, hidalgos notorios de sangre de la casa y solar de Villarpandín como hijos de dho su padre y nietos de Alvaro de Navia y bisnietos de $\mathrm{P}^{\circ}$ Albarez de Laçeana por lignea reta de baron descendientes de dha casa de Vilarpandín=Y don $\mathrm{P}^{\circ}$ Bolaño Rivadeneyra hijodalgo notorio de sangre de la casa y solar de Billarpandin como hijo lejitimo de Diego Garcia de Ulloa y nieto de P. ${ }^{\circ}$ de Bolaño Rivadeneyra y bisnieto de Basco Sánchez de Ulloa y rebisnieto de Diego Gómez de Cancelada, vecinos que fueron del lugar de Quintá de quien es descendiente por lignea reta de barón y de Gonzalo Méndez de Navia y Lamas dueño que fue de dha casa y solar de Billarpandín y dho don $\mathrm{P}^{\circ}$ Bolaño tiene por sus hijos lejítimos a don Joseph Bolaño Rivadeneyra y a don Jacinto Bolaño y a don $\mathrm{P}^{\circ}$ Bolaño vecinos del dho lugar de Quintá donde lo es el dho su padre... Cfr. Ibid., folios 1161 y vto». 
dirigida a la justicia y regimiento del concejo de Castropol al objeto de que procediese a tildar y borrar aquel tipo de expresiones de los padrones posteriores a la Provisión de 23 de mayo de $1786^{66}$.

${ }^{66}$ Las correcciones afectan a todas las expresiones consideradas gratuitas, tales como «caballeros notorios de los solares de...», «señores de la casa principal de..., «caballeros notorios de las casas y solares...», entre otras. Se transcribe aquí una pequeña parte de la enmienda correspondiente al padrón de la parroquia de San Esteban de Piantón del año 1789: «...se tildó, testó, y Borró; en la de Don Jacinto Pablo Valledor, y Presno, en la Quinta del Outeiro la Vega, las expresiones que dicen = Cavallero notorio de los solares conocidos de Valledor, Presno, la Vega, Santalla, Reimondo, Pardo y Osorio, y señor propio de las casas solariegas de Valledor, Presno, la Vega, Santalla, y de la jurisdicción de Montealegre $=$ y señora de la casa prinzipal de Tapia $=$ Caballeros notorios de las casas, y solares = En la de Don Garzia Ramón hixo de Don Jazinto Valledor lo que dize: y señores = En la de Doña maría del carmen hixa del Don Jacinto, y muger de Don Juan Pardo Donlebún lo que expresa = Dueño y Señor de la Casa Prinzipal de Donlebún $=$ Cavalleros $=$ notorios de las mismas casas y solares...». Cfr. AAV, Fondos del Concejo de Castropol, Sección Padrones, Caja 00892. 